\title{
Pelatihan Guru SD di Tangerang: Implementasi TPR dalam Meningkatkan Penguasaan Bahasa Inggris
}

\author{
Ishak*1, Euis Yanah Mulyanah $^{2}$ \\ 1,2Universitas Muhammadiyah Tangerang \\ ${ }^{1}$ Program Studi Akuntansi, Fakultas Ekonomi dan Bisnis, Universitas Muhammadiyah Tangerang \\ 2Program Studi Pendidikan Bahasa Inggris, Fakultas Keguruan dan Ilmu Pendidikan, Universitas \\ Muhammadiyah Tangerang \\ *e-mail: ishak@umt.ac.id ${ }^{1}{ }_{2}$ euis@umt.ac.id $^{2}$
}

\begin{abstract}
This Community Service aims to motivate and improve English teachers' skills in Tangerang. Based on Mulyanah's research from the University of Muhammadiyah Tangerang in 2018 there were 26\% differences in English students' proficiency between the regency and city areas; it was seen in the scores of students' mastery of English. The problems are the teacher's lack of competence in English proficiency it caused by nonlinear fields of science so the teachers need English training. The participants were attended by 20 English teachers who were in the Paku Haji district-Tangerang. The training is divided into pre-test, treatment, using the Total Physical Responses (TPR) method by using English Instructions in the teaching-learning process, and post-test. The results of the training are 1) Increased teacher motivation in learning English, 2) Increased confidence using English both in the classroom and outside the classroom, 3) Increased teacher competence in their English subjects.
\end{abstract}

Keywords: TPR, English Proficiency, Teacher Training

\begin{abstract}
Abstrak
Pengabdian kepada masyarakat ini bertujuan untuk memotivasi dan meningkatkan kemampuan guru bahasa Inggris di Tangerang. Berdasarkan penelitian Mulyanah dari Universitas Muhammadiyah Tangerang tahun 2018, terdapat 26\% perbedaan kemampuan bahasa Inggris siswa antara daerah Kabupaten dan kota; itu terlihat dari nilai penguasaan siswa dalam bahasa Inggris. Masalahnya adalah kurangnya kompetensi guru dalam bahasa Inggris yang disebabkan oleh bidang ilmu yang tidak linear sehingga perlu adanya pelatihan guru bahasa Inggris. Peserta diikuti oleh 20 orang guru bahasa Inggris yang berada di Kecamatan paku Haji-Tangerang. Pelatihan ini dibagi menjadi pre-Test, perlakuan, aplikasi metode Total Physical Responses (TPR) dengan menggunakan English Instruction dalam proses belajar-mengajar, dan posttest. Hasil pelatihan adalah 1) peningkatan motivasi guru dalam belajar bahasa Inggris, 2) peningkatan kepercayaan diri guru dalam menggunakan bahasa Inggris baik di dalam kelas maupun di luar kelas, 3) meningkatkan kompetensi guru dalam bidang bahasa Inggris mereka.
\end{abstract}

Kata kunci: TPR, Penguasaan Bahasa Inggris, Pelatihan Guru

\section{PENDAHULUAN}

Pengabdian Kepada Masyarakat ini perlu dilakukan berdasarkan data rujukan dari hasil sebuah penelitian Mulyanah dari Universitas Muhammadiyah Tangerang pada skema PDP Ristekdikti di Kabupaten Tangerang 2018. Dari data penelitian tersebut ditemukan permasalahan yaitu 97\% di Kabupaten Tangerang terdapat guru Bahasa Inggris yang tidak linier dengan bidang keilmuannya sehingga mengakibatkan terdapatnya perbedaan kompetensi dalam penguasaan bahasa Inggris pada siswa SD di kabupaten tersebut, tentunya hal tersebut menimbulkan perbedaan peningkatan penguasaan Bahasa Inggris pula terhadap siswa SD yang terdapat di Kabupaten dengan yang terdapat di Kota Tangerang. Perbedaan ini dapat dilihat dari adanya peningkatan pada skor rerata nilai siswa SD di Kabupaten mencapai 49.00 sementara siswa SD yang terdapat di kota mencapai 66.67. Perbedaan nilai rata-rata tes bahasa Inggris diantara dua sekolah tersebut adalah 26\% (Mulyanah, 2018). Berdasarkan hasil nilai tersebut maka terlihat adanya perbedaan nilai dalam penguasaan bahasa Inggris siswa SD yang terdapat di Kabupaten Tangerang lebih rendah nilainnya apabila dibandingkan dengan di wilayah perkotaan. Atas dasar alasan tersebut maka sangat diperlukan pengabdian ini meningkatkan prestasi belajar siswa melalui peningkatan penguasaan berahasa Inggris (Warman et al., 2020) untuk Guru Sekolah 
Dasar di Kabupaten Tangerang dengan menggunakan metode TPR dalam peningkatan penguasaan Bahasa Inggris yang lancar dan fasih (Oktavia, 2019). Pengabdian ini, menggunakan pendekatan kuantitatif deskriptif yang pengabdi pilih yaitu disain quasi experimental dan jenis disain nonequvalen control group dengan menggunakan prates dan pascates pada kelompok eksperimen dan kelompok control dengan tujuan menemukan tingkat skor perbandingan sebelum dan sesudah mendapatkan perlakuan.

Untuk mengatasi permasalahan diatas, maka sangat diperlukan adanya pengabdian untuk peningkatan kemampuan berbahasa Inggris guru Sekolah Dasar di wilayah Kabupaten Tangerang yaitu dengan metode TPR (Ishak, 2019a). TPR merupakan pengantar untuk pendekatan pengajaran yang dikenal sebagai respon fisik total (Ishak, 2019b). Tujuannya adalah untuk mempertahankan motivasi awal dan mempertahankan rasa ingin tahu dan minat guru sehingga mengembangkan keinginan untuk belajar bahasa, terutama dalam bahasa Inggris dengan mudah dan cepat karena menurut (Setyanigtyas, 2018). Pembelajaran adalah sebuah aktifitas yang dirancang oleh guru dalam membantu siswa untuk belajar sesuai dengan kemampuannya dengan sistematis melalui perencanaan, aksi dan evaluasi" Jadi, bukan hanya siswa yang aktif akan tetapi dalam pengajaran siswa tersebut harus terdapat aksi didalamnya, dengan metode TPR ini dapat merangsang siswa untuk melakukan apa yang diinstruksikan oleh guru karena siswa Sekolah Dasar pada umumnya mempunyai konsentrasi yang pendek terutama dalam mengingat kosa kata (Hendracipta, 2018). Sehingga utnuk membuat mereka menyukai kosa kata adalah dengan bagaimana guru memperkenalkan kosakata tersebut dengan metode yang menarik. TPR juga dapat meningkatakan ketertarikan siswa dalam mempelajari bahasa Inggris karena siswa akan termotivasi (binti Bachtiar, 2016) akan tetapi pemerolehan kosa kata akan berhasil apabila melalui metode apa yang akan dipakai dan seberapa cepat siswa akan memahami bahasa Inggris melalui metode tersebut [6], bukan hanya metode, selanjutnya peran guru sangat diperlukan untuk memotivasi siswa dalam memapelajari bahas Inggris tersebut karena kosa kata erat kaitannya dengan memori atau daya ingat siswa untuk membuat siswa termotivasi maka digunakannlah metode TPR (FENG Shan-shan, 2017).

Prosedur pelatihan berbahasa Inggris Melalui TPR. Guru akan diberikan 6 kali pertemuan dalam mendapatkan materi English instruction vocabulary dan TPR metod. Selain itu mereka akan diberikan sebuah buku yang didalamnya khusus terdapat berbagai intruksi dalam bahasa Inggris beserta cara membacanya yang sudah dilengkapi dengan phonetice symbol (Cihon et al., 2016). Hal tersebut bertujuan agar pemerolehan kosa kata guru dalam mengimplementasikan pengajaran kepada siswa lebih mudah dan benar dalam hal pengucapannya (Liu, 2016). Menurut (Sariyati, 2011), TPR method mudah diterapkan kepada siswa dikarnakan metode ini memerlukan gerakan-gerakan siswa dalam memberikan intruksi di dalam kelas siswa bersemangat dalam pembelajaran.

Berdasarkan latar belakang diatas perlu dirumuskan masalah pengabdian kepada masyarakat ini bahwa penguasaan bahasa Inggris untuk siswa SD di desa lebih rendah bila dibandingkan dengan siswa SD di kota, sehingga perlu adanya pelatihan pengenalaan kosa kata dan intruksi-inruksi dalam bahasa kepada guru Inggris dengan menggunakan metode yang menarik agar dapat meningkatkan minat dan prestasi siswa sehingga tidak tertinggal dengan siswa SD yang berada di kota agar mendapatkan output yang sesuai dengan keinginan pemerintah. Pengabdian ini bertujuan dalam rangka meningkatakan kemampuan guru bahasa Inggris di wilayah Tangerang khususnya di wilayah Kabupaten.

\section{METODE}

Dalam pengabdian ini, pengabdi menggunakan pendekatan kuantitatif, karena melakukan suatu cara untuk membandingkan kelompok. Jenis disain diatas yang digunakan adalah disain nonequivalent control group dengan menggunakan prates dan pascates pada kedua kelompok baik kontrol maupun eksperimen untuk menemukan skor perbandingan pada tingkat penguasaan sebelum ataupun sesudah mendapatkan treatment. Untuk kelompok experiment adalah guru SDN 
Buaran Bambu 1 Kabupaten Tangerang dan kelompok kontrol sebagai pembanding adalah guru SDN Periuk 4 Kota Tangerang. Sampel yang diambil adalah 40 orang guru yang berada di Tangerang dari kedua sekolah tersebut. Terdapat tiga teknik dalam pengumpulan data diantaranya adalah Observasi, prates dan pascates. Dalam observasi bertujuan untuk memperoleh data autentik. Prates dan pascates pengabdi memberikan tes tertulis berupa 140 pertanyaan dalam Bentuk pertanyaan TOEFL. Pertanyaan terdiri dari 50 butir soal untuk listening Comprehension, 50 butir soal untuk structure and written expression dan 40 soal untuk Reading compehension. Soal dalam bentuk multiple choice dengan skor 1 untuk yang benar dan skor 0 untuk yang salah. Dalam perhitungan nilai Toefl skor dari setiap section akan dikonversikan sesuai dengan tabel daftar nilai konversi TOEFL pada umumnya, untuk mengetahui nilai akhir yaitu nilai TOEFL. Setelah mengumpulkan data, pengabdi menganalisis, mendeskripsikan dan akhirnya menyimpulkan. Data akan dianalisis dengan menggunakan analisis statistik dengan menghitung nilai rata-rata dari pra-test dan post-test untuk mengetahui apakah ada perbedaan yang signifikan pada kedua kelompok kota dan kabupaten setelah mendapatkan pelatihan.

\section{HASIL DAN PEMBAHASAN}

\subsection{Observasi}

Berdasarkan hasil observasi, Penagabdi menemukan beberapa hal diantaranya yang berkaitan denagn profil sekolah, profil guru dan peserta didik yang berada di 2 sekolah tersebut, baik SDN Periuk 4 kota Tangerang dan SDN Buaran Bambu 1 Kabupaten Tangerang. Menurut data yang diperoleh bahwa guru bahasa Inggris di SDN buaran Bambu 1 adalah terdapatnya guru bahasa Inggris yang bukan dari lulusan program studi pendidikan bahasa Inggris akan tetapi guru tersebut lulusan D3 akademi pariwisata dan mahasiswa pendidikan agama islam, hal tersebut dipaparkan oleh kepala sekolah SDN Buaran Bambu 1 yang sangat keterbatasan SDM dalam hal tenaga pengajar atau guru, jarang ada yang bersedia untuk mengajr di SDN tersebut selain dari segi honor yang belum sesuai hal tersebut diakibatkan dari tempat yang jauh dari pusat kota serta rendahnya kesadaran masyarakat setempat dalam bidang pendidikan.

\subsection{Tes}

\subsubsection{Hasil Skor Prates dan Pascates Kelompok Eksperimen}

Tabel 1. Hasil Skor Prates dan Pascates Kelompok Eksperimen

\begin{tabular}{ccccc}
\hline Eksperimen & Min & Maks & Rerata & Std.Dev \\
\hline Prates & 31 & 65 & 45.20 & 7.90 \\
Pascates & 30 & 80 & 48.60 & 13.15 \\
Gain & 9 & 15 & 3.45 & \\
Persentase & $30 \%$ & $18.75 \%$ & $7.10 \%$ & \\
\hline
\end{tabular}

Berdasarkan tabel 1, terlihat terdapatnya peningkatan yang signifikan yaitu diperoleh pada prates yang mencapai 45.20 dan pascates dengan nilai 48.60 sehingga peningkatan presentase dari kedua nilai tersebut adalah mencapai $7.10 \%$. hal tersebut berdasarkan pemerolehan hasil tes kemampuan bahasa Inggris dalam bentuk TOEFL Test diperoleh 19 guru yang terdapat pada tingkat elementary dan 1 guru yang mencapai tingkat low intermediate, dimana tingkat elementary berada pada nilai 310 sampai dengan 420 dan tingkat low intermediate berada pada nilai 420 sampai kepada 480 .

\subsubsection{Hasil Prates dan Postest Kelas Kontrol}

Tabel 2. Hasil Nilai Prates dan Pascates Kelas Kontrol

\begin{tabular}{ccccc}
\hline Control & Min & Maks & Rerata & Std.Dev \\
\hline Prates & 27 & 64 & 42.25 & 9.21
\end{tabular}




\begin{tabular}{ccccc} 
Pascates & 26 & 86 & 41.95 & 14.42 \\
Gain & 1 & 22 & 0.30 & \\
Presentasi & $3.85 \%$ & $25.58 \%$ & $0.76 \%$ & \\
\hline
\end{tabular}

Pada tabel 2 diperoleh nilai rerata dari pratest dan pascates pada kelas kontrol adalah $0.76 \%$ peningkatan tersebut terlihat dari data pratest dimana 20 guru sebagai sample di kelas kontrol ini berada pada tingkat elementary dengan skor nilai diantara 310 sapai dengan 420 . Sementara data pascates diperoleh 18 guru yang berada pada tingkat elementary dengan skor, 1 guru berada pada tingkat low intermediate diantara skor nilai 420 sampai dengan 480 dan 1 guru terdapat pada tingkat high intermediate diantara skor nilai 480 sampai dengan 520 . Selanjutnya adalah membandingkan kedua nilai pascates yaitu pada kelas eksperimen maupun kelas kontrol sebagai berikut:

Tabel 3. Hasil Nilai Pascates Kelas Eksperimen dan Kelas Kontrol

\begin{tabular}{ccccc}
\hline \multirow{2}{*}{ KELAS } & \multicolumn{3}{c}{ PASCATES } \\
\cline { 2 - 5 } & Min & Maks & Rerata & Std.Dev \\
\hline Ekperimen & 30 & 80 & 48.6 & 13.15 \\
Control & 26 & 86 & 41.95 & 14.42 \\
Gain & 4 & 6 & 6.65 & \\
Presentasi & $15.38 \%$ & $6.98 \%$ & $0.16 \%$ & \\
\hline
\end{tabular}

Dari tabel 3, Terdapat perbedaan nilai yang tidak terlalu signifikan antara kelas ekperimen dan kelas kontrol dari hasil nilai pascates, dimana kelas eksperimen diperoleh nilai rerata sebesar 48.6 dan kelas kontrol sebesar 41.95 hal tersebut didapat dari hasil perolehan nilai presentasi yang mengalami peningkatan sebesar $0.16 \%$ setelah melatihan perlakuan. Hal tersebut dapat diilustrasikan pada diagram batang dibawah ini:

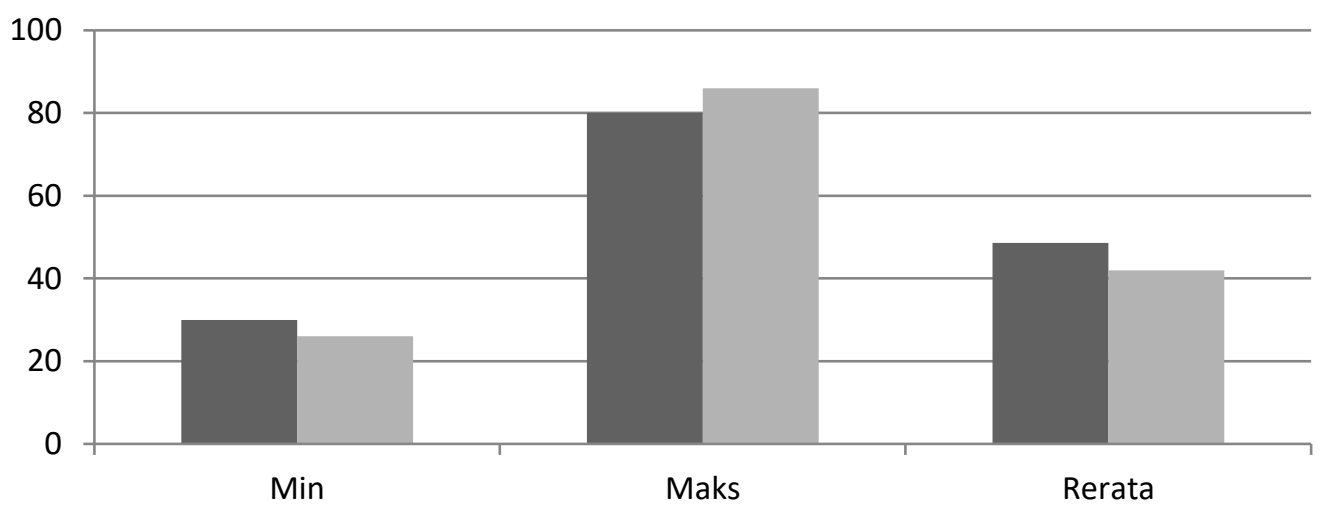

Gambar 1. Nilai Gain Pascates Kelas Ekperimen dan Kontrol

Dari Gambar 1 dapat terlihat bahwa perbedaan antara kelompik yang tidak diberikan pelatiahan sebelah kiri dengan yang diberikan pelatihan sebelah kanan, pascates pada nilai minimal score kelompok kelas yang diberikan pelatihan yang lebih tinggi, akan tetapi pada nilai terbesar kelompok pelatihanlah yang terbesar yang mengalami kenaikan pada pascates setelah mendapatkan perlakuan.

\section{KESIMPULAN}

Dari hasil observasi, tes dan enam kali pelatihan dapat disimpulkan bahwa, terdapat perbedaan peningkatan pada kedua kelompok baik di kota maupun di Kabupaten Tangerang. Hal tersebut dapat dilihat dari perbedaan skor rerata dimana guru yang berada di Kabupaten Tangerang mendapatkan nilai tertinggi sertelah mendapatkan perlakuan sehingga dapat 
disimpulkan bahawa pemberian pelatihan dengan menggunakan TPR dapat meningkatkan motivasi dan kemampuan Guru SD yang terdapat di Tangerang Indonesia. Karena diperoleh data pascates terdapat 13 guru yang berada pada elementary level, 4 guru pada level low intermediate, dan 3 guru berada pada tingkat paling tinggi yaitu advance. Sedangkan pada kelas control 18 guru berada pada elementary level, 1 guru pada low intermediate level dan 1 guru berada pada advance level. Hal tersebut menunjukan adanya perbedaan diantara dua kelas tersebut dengan tingkat presentasi sebesar 6,65 atau $0.16 \% \%$. Maka dapat dilihat bahawa TPR dapat meningkatkan kemampuan bahasa Inggris pada guru SD di Kota Tangerang Indonesia.

\section{DAFTAR PUSTAKA}

Binti Bachtiar, E. S. (2016). Kompetensi Kognitif Pembelajaran Apresiasi Sastra Di Sekolah Dasar. Gramatika STKIP PGRI Sumatera Barat, 2(1), 1-11. https://doi.org/10.22202/jg.2016.v2i1.1395

Cihon, T. M., Cihon, J. H., \& Bedient, G. M. (2016). Establishing a common vocabulary of key concepts for the effective implementation of applied behavior analysis. International Electronic Journal of Elementary Education, 9(2SpecialIssue), 337-348.

FENG Shan-shan. (2017). An Application of Total Physical Response to Primary English Teaching-A Case Study of Qingtong Primary School. US-China Foreign Language, 15(1), 3642. https://doi.org/10.17265/1539-8080/2017.01.006

Hendracipta, N. (2018). AND ITS LEARNING PROCESS OF CHARACTER EDUCATION-. 4(1).

Ishak, M. (2019a). IMPLEMENTASI METODE TOTAL PHYSICAL RESPONS (TPR) DALAM MENINGKATKAN KEMAMPUAN BA\}IASA INGGRIS GURU SD DI TANGERANG.

Ishak, M. (2019b). IMPROVING THE ENGLISH SKILL OF PRIMARY TEACHERS. 5(2), 150-158. https://doi.org/http://dx.doi.org/10.30870/jpsd.v5i2.5895.g4405

Liu, P. L. (2016). Mobile english vocabulary learning based on concept-mapping strategy. Language Learning and Technology, 20(3), 128-141.

Mulyanah. (2018). PENERAPAN METODE TOTAL PHYSICAL RESPONSE (TPR) DALAM PENGUASAAN KOSA KATA BAHASA INGGRIS SEKOLAH DASAR (SD). In Universitas Muhammadiyah Tangerang.

Oktavia, Y. yunisa. (2019). Pembinaan Budaya Literasi Berbasis Android untuk Kemahiran Bahasa Inggris dan Kesantunan Berbahasa. Dinamisia :Jurnal Pengabdian Kepada Masyarakat, 3, 90100. https://doi.org/10.31849/dinamisia.v3i2.2871

Sariyati, I. (2011). Efektivitas Penggunaan Metode Total Physical Response dalam Meningkatkan Penguasaan Vocabulary Bahasa Inggris pada Siswa Sekolah Dasar. 2003, 38-49.

Setyanigtyas, E. W. (2018). PENGARUH PENERAPAN MODEL PEMBELAJARAN PICTURE AND PICTURE DAN MODEL MAKE A MATCH TERHADAP HASIL BELAJAR SISWA. 4(1).

Warman, J. S., Mardian, V., Suryani, L., Fista, F. R., \& Irwan, I. (2020). Program Pelatihan Penigkatan Kemampuan Bahasa Inggris Anak-Anak Panti Asuhan Melalui Pemberdayaan Mahasiswa. Dinamisia: Jurnal Pengabdian Kepada Masyarakat, 3(2), 280-285. https://doi.org/10.31849/dinamisia.v3i2.3304 